\title{
Clinical significance of LGR5 and CD44 expression in locally advanced rectal cancer after preoperative chemoradiotherapy
}

\author{
SUSUMU SAIGUSA, YASUHIRO INOUE, KOJI TANAKA, YUJI TOIYAMA, KOHEI MATSUSHITA, \\ MIKIO KAWAMURA, YOSHINAGA OKUGAWA, JUNICHIRO HIRO, KEIICHI UCHIDA, \\ YASUHIKO MOHRI and MASATO KUSUNOKI
}

Department of Gastrointestinal and Pediatric Surgery, Mie University Graduate School of Medicine, Tsu, Mie 514-8507, Japan

Received May 18, 2012; Accepted July 23, 2012

DOI: $10.3892 /$ ijo.2012.1598

\begin{abstract}
LGR5, known as a target of Wnt signaling, has been reported as an intestinal stem cell marker. Recent reports showed that LGR5 was associated with carcinogenesis and tumor invasion in colorectal cancer. CD44 is a ubiquitously expressed cell adhesion molecule and also a potential cell surface marker on colon cancer stem cells. Both LGR5 and CD44 have been also reported to be Wnt signal targets. The aim of this study was to investigate the association of these markers with clinical outcome in rectal cancer after preoperative chemoradiotherapy (CRT). A total of 52 rectal cancer specimens were obtained from patients who underwent preoperative CRT. We performed transcriptional and immunohistochemical analyses, and retrospectively studied the association of LGR5 and CD44 expression levels with clinical outcomes. For CD44, its expression in cancer stroma was also evaluated. The levels of cancer $L G R 5$ and $C D 44$ gene expression were significantly and positively correlated. $L G R 5$ gene expression level in cancer and positivity of $C D 44$ gene expression in cancer stroma were significantly correlated with disease recurrence. Elevated cancer $L G R 5$ gene expression and positive $C D 44$ gene expression in cancer stroma were significantly associated with poor recurrence-free and overall survival. Multivariate analysis indicated that positivity of stromal CD44 gene expression was an independent prognostic factor for the recurrence and overall survival of patients with rectal cancer after preoperative CRT. In conclusion, LGR5 and CD44 expression may be coordinately associated with tumor relapse in locally advanced rectal cancer after preoperative CRT.
\end{abstract}

\section{Introduction}

Rectal cancer is one of the most common cancers in Japan as well as the western world. Preoperative CRT followed by total

Correspondence to: Dr Susumu Saigusa, Department of Gastrointestinal and Pediatric Surgery, Mie University Graduate School of Medicine, 2-174 Edobashi, Tsu, Mie 514-8507, Japan

E-mail: saigusa@clin.medic.mie-u.ac.jp

Key words: LGR5, CD44, rectal cancer, chemoradiotherapy, disease recurrence, poor prognosis mesorectal excision (TME) has improved the rates of survival, sphincter preservation, and local pelvic control (1-4). Despite significant improvements in the management of rectal cancer, tumor relapse remains the major cause of mortality in patients with preoperative CRT followed by TME. Further improvements in the survival rate cannot be achieved without better control of post-surgical local and distal recurrence.

Leucine-rich repeat-containing $\mathrm{G}$ protein-coupled receptor 5 (LGR5), also known as GPR49 (G-protein-coupled receptor 49), is closely related to members of the glycoprotein hormone receptor subfamily with seven transmembrane domains and is a target of Wnt signaling. LGR5 is a potential marker for stem cells in the small intestine and colon (5-7). Sato et al demonstrated that a single LGR5-positive cell could initiate a crypt villus-like structure and generate a continuously expanding, self-organizing epithelial structure reminiscent of normal gut without stroma tissue (8). On the other hand, it has been reported that LGR5 expression is implicated in colorectal carcinogenesis $(7,9)$. Uchida et al reported that LGR5 might be implicated not only in early events but also in late events in colorectal tumorigenesis (10). From these findings, we hypothesized that LGR5 expression might participate in the maintenance and proliferation of residual cancer cells after CRT.

The transmembrane glycoprotein CD44, a hyaluronan receptor, is an adhesion molecule with multiple splice variant isoforms, which facilitates both cell-cell and cell-extracellular matrix (ECM) interactions (11,12). Additionally, CD44 is an important cell surface marker for isolating colon cancer stem cells (CSCs) (13-15). CD44 is expressed by most human cell types and is implicated in a wide variety of physiological and pathological process, including lymphocyte homing and activation, and cell migration $(16,17)$. CD44 is consistently overexpressed in many types of carcinomas including colon cancer and participates in tumor proliferation, invasion, and metastasis $(16,18,19)$. CD44 activation is important to consider in the metastasis cascade due to stimulating tumoral ECM $(12,18)$. Lakshman et al demonstrated that CD44 expression, and, more importantly the v3-10 isoform, promoted resistance to apoptosis in vitro (20). Therefore, we hypothesized that CD44 might be implicated in resistance to CRT and distant relapse in rectal cancer after preoperative CRT. To the best of our knowledge, CD44 expression after CRT has scarcely been evaluated. 
Both LGR5 and CD44 have been reported to be Wnt signal targets (7,21-23) and known as stemness markers (21). In this study of locally advanced rectal cancer patients treated with preoperative CRT, we used transcriptional and immunohistochemical analyses to investigate the correlation between LGR5 and CD44 expression, and the association of their expression with clinical outcomes. For CD44, we examined expression in both cancer and stromal cells.

\section{Materials and methods}

Patients and specimens. From 2001 to 2008, 64 patients with rectal cancer received preoperative CRT followed by surgery at our institute. The criteria for induction of preoperative CRT in our institute are as follows. Patients must be $\leq 80$ years old, in clinical stage II/III based on the International Union Against Cancer's TNM classification, with no evidence of distant metastases, no invasion of external sphincter muscle nor elevator muscle of the anus, and no evidence of deep venous thrombosis. Five patients without curative surgery were excluded in this study. Additionally, we excluded 5 patients with pathological complete response after preoperative CRT because cancer cells were not obtained. A total of 54 formalin-fixed, paraffinembedded (FFPE) specimens were investigated for this study. The study design was approved by the ethics review board of Mie University Hospital. All patients signed informed consent forms for their tissues to be used in this study.

5-fluorouracil-based chemoradiotherapy regimen. Patients with rectal cancer were treated with short-course (a dose of $20 \mathrm{~Gy}$ in 4 fractions) or long-course (a dose of $45 \mathrm{~Gy}$ in 25 fractions) radiotherapy using a 4-field box technique with concurrent chemotherapy to take advantage of 5-fluorouracil (5-FU) radiosensitization. Patients underwent concurrent pharmacokinetic modulation chemotherapy (intravenous infusion of 5-FU: $600 \mathrm{mg} / \mathrm{m}^{2}$ for $24 \mathrm{~h}$, and tegafur-uracil (UFT) given as $400 \mathrm{mg} /$ $\mathrm{m}^{2}$ orally for 5 days. This regimen was based on the previously tested combination of continuous infusion of 5-FU and oral administration of UFT (24). Short-course radiotherapy in our institute is different from standard short-course radiotherapy, $25 \mathrm{~Gy}$ in 5 fractions. There are several reasons that we designed the present regimen. We calculated a biologically equivalent dose (BED) of 20 Gy in 4 fractions using a linear quadratic model (25) and its BED was $30 \mathrm{~Gy}(\alpha / \beta$ ratio: $10 \mathrm{~Gy})$. We understand that BED: 30 Gy had a sufficient efficacy reducing the local failure of radiotherapy (26). Forty-two patients received short-course radiotherapy with chemotherapy over 1 week. The remaining 10 patients received long-course radiotherapy with chemotherapy for 4 weeks. The time interval between preoperative CRT and surgery was 2-3 weeks in short-course irradiation patients, and 4-6 weeks in long-course irradiation patients. All patients underwent standard surgery including total mesorectal excision, and received 5-FU based adjuvant chemotherapy after surgery for 6 months to 1 year.

Histopathological tumor regression after CRT. The histopathological response of CRT was evaluated using Rödel tumor regression grading (TRG) system (27) and 3-point Ryan system (28). Each TRG was classified by two investigators in a blinded fashion without knowledge of the clinical and pathological information. Rödel TRG system is classified into five categories: grade 0 , no regression; grade 1, minor regression (dominant tumor mass with obvious fibrosis in $\leq 25 \%$ of the tumor mass); grade 2, moderate regression (dominant tumor mass with obvious fibrosis in $26-50 \%$ of the tumor mass); grade 3 , good regression (dominant fibrosis outgrowing the tumor mass; i.e., $>50 \%$ tumor regression); and grade 4, total regression (no viable tumor cells, only fibrotic mass). We categorized responders as patients with TRG 3 to 4, while non-responders were TRG 0-2. Three-point Ryan system is devised by combining TRG1 (no viable cancer cells) and TRG2 (single cells or small groups of cancer cells) to form one category as 3-point TRG1, and TRG3 (residual cancer outgrown by fibrosis) into 3-point TRG2, combining TRG4 (significant fibrosis outgrown by cancer) and TRG5 (no fibrosis with extensive residual cancer) into 3-point TRG3. Patients with 3-point TRG1 and 2 were categorized as responders and patients with 3-point TRG were categorized as non-responders.

Microdissection and RNA extraction from formalin-fixed paraffin-embedded (FFPE) specimens. Microdissection of FFPE was performed as previously described (29). Microdissected specimens were digested with proteinase $\mathrm{K}$ in lysis buffer containing Tris- $\mathrm{HCl}$, ethylenediaminetetraacetic acid, and sodium dodecyl sulfate, as previously published (30), with minor modifications. RNA was purified by phenol and chloroform extraction. Isolated RNA was purified using ethanol precipitation. The concentration and quality of RNA was measured with UV absorbance at 260 and $280 \mathrm{~nm}$ (A260/280 ratio).

cDNA synthesis. To reverse transcribe the fragmented mRNA from FFPE tissue materials, we used random hexamer priming, instead of oligo(dT)-based priming. cDNA was synthesized with random hexamer and Superscript III reverse transcriptase (Invitrogen, Carlsbad, CA) according to the manufacturer's instructions.

Quantitative real-time polymerase chain reaction ( $q R T-P C R$. qRT-PCR analysis was carried out with the SYBR Green PCR Master Mix (Applied Biosystems, Foster City, CA) using the Applied Biosystems 7500 Real-Time PCR system according to the manufacturer's instructions. Primers for $L G R 5, C D 44$, $C T N N B 1$ ( $\beta$-catenin) and ACTB ( $\beta$-actin) were designed with Primer3 software (Biology Workbench Version 3.2, San Diego Supercomputer Center, at the University of California, San Diego). Sequences were as follows: $L G R 5$-specific primers (sense, GATGTTGCTCAGGGTGGACT, and antisense, GGG AGCAGCTGACTGATGTT); $C D 44$-specific primers (sense, CGGACACCATGGACAAGTTT, and antisense, CACGTGGA ATACACCTGCAA), CTNNB1-specific primer (sense, TGTT CGTGCACATCAGGATAC and antisense, GCTCCGGTACA ACCTTCAAC) and ACTB (sense, ACAGAGCCTCGCCTT TGC, and antisense, GCGGCGATATCATCATCC). PCR was performed in a final volume of $25 \mu \mathrm{l}$ with a SYBR Green PCR Master Mix, using $1 \mu \mathrm{l} \mathrm{cDNA}$, and $400 \mathrm{nM}$ of each primer for the respective genes. Cycling conditions were $50^{\circ} \mathrm{C}$ for $2 \mathrm{~min}$ and $95^{\circ} \mathrm{C}$ for $10 \mathrm{~min}$, followed by 40 cycles at $95^{\circ} \mathrm{C}$ for $15 \mathrm{sec}$ and $60^{\circ} \mathrm{C}$ for $1 \mathrm{~min}$. 
Relative gene expression levels of LGR5 and CD44. Relative gene expression levels were determined by the standard curve method. The standard curves and line equations were generated using 5-fold serially diluted solutions of cDNA from qPCR Human Reference Total RNA (Clontech, Mountain View, CA) for $L G R 5$ and $C D 44$. All standard curves were linear in the analyzed range with an acceptable correlation coefficient $\left(R^{2}\right)$. The amount of target gene expression was calculated from the standard curve followed by quantitative normalization of cDNA in each sample using $A C T B$ gene expression as an internal control. Target gene mRNA levels are given as ratios to $A C T B$ mRNA levels. RT-PCR assays were done in duplicate for each sample and the mean value was used for calculation of the mRNA expression levels.

Immunohistochemistry for LGR5 and CD44. Immunohistochemistry was performed as previously described (29). LGR5 (GPR49, rabbit monoclonal antibody, clone EPR3065Y, Epitomics, CA, USA) and human CD44H antibody (monoclonal mouse $\operatorname{IgG}_{2 \mathrm{~A}}$, clone no. $2 \mathrm{C} 5, \mathrm{R} \& \mathrm{D}$ Systems, MN, USA) as primary antibodies were used at dilutions of 1:100 and 1:1000 respectively. All sections were counterstained with hematoxylin, and were dehydrated and mounted. Negative controls were also run simultaneously. LGR5 and CD44 expression was evaluated semi-quantitatively in a blinded fashion without knowledge of clinical and pathological information. We defined the high expression group as cases in which $>50 \%$ of cancer cells. For the evaluation of immunoreactivity of CD44 in stroma, we defined the high expression group as cases that its strong expressions were localized in cancer stroma surrounding cancer nests.

Statistical analyses. All statistical analyses were performed using StatView 5.0 for Windows (SAS Institute Inc., Cary, NC). Values of each target gene are expressed as median values (inter-quartile range) in tables. Associations between continuous variables and categorical variables were evaluated using MannWhitney $U$ tests for two groups. The $\chi^{2}$ test was also used to assess the significance of the correlation between categorical variables. A non-parametric receiver operating characteristic (ROC) analysis was performed to calculate the best cutoff value for each gene expression level that would be predictive of recurrence and survival, using Medcalc 7.2 for Windows (Mariakerke, Belgium). Recurrence-free survival (RFS) and overall survival (OS) time were calculated from the date of surgery to the date of disease recurrence and patients' death, respectively. RFS and OS probabilities were calculated using the Kaplan-Meier product limit method; intergroup differences were determined using a log-rank test. The influence of distant recurrence and survival predictors identified univariate analysis was accessed by multivariate analysis using Cox's proportional hazards model. Two-sided P-values < 0.05 were considered statistically significant.

\section{Results}

Patient and tumor characteristics. A total of 54 total-RNA were obtained from FFPE specimens of rectal cancer with preoperative CRT. Two specimens were excluded as the $A C T B$ expressions were very low and without reproducibility. Therefore, 52 patients were included in this study. Table I shows patient characteristics

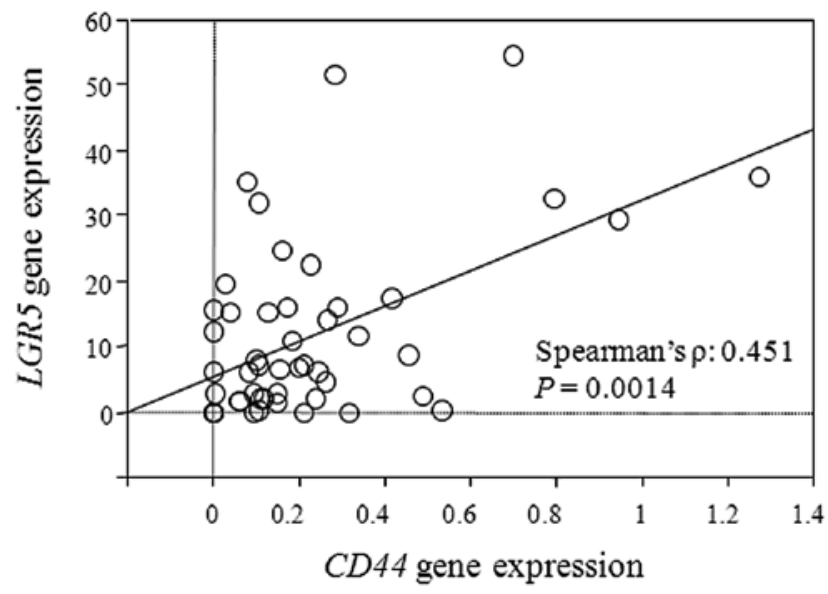

Figure 1. Positive correlation between $L G R 5$ and $C D 44$ gene expression in cancer cells.

and the association of the gene expression levels of $L G R 5$ and $C D 44$ with clinicopathological variables. The median age was 64.5 years (range 37-78 years) and the male to female ratio was 3.7:1. The post-CRT pathological T stages were ypT1 $(n=5)$, ypT2 $(n=12)$, ypT3 $(n=33)$, and ypT4 $(n=2)$. Seventeen patients (33\%) had lymph node metastases. Forty-four tumors $(85 \%)$ showed well or moderately differentiated adenocarcinoma histology. Three patients $(6 \%)$ had local recurrence alone. A total of 12 patients $(23 \%)$ had distant recurrence. Patterns of distant recurrence were seen as liver and lung metastases in 2 patients, lung metastasis alone in 6 patients, and peritoneal metastasis in 2 patients. Rödel TRG system was as follows: grade 0,0 patients; grade 1, 10 patients; grade 2, 22 patients; grade 3, 19 patients; and grade 4, 1 patient. 3-point Ryan TRG was as follows: TRG1, 14 patients; TRG2, 23 patients; TRG3, 15 patients. The median follow-up period was 67 months (range 22-129 months).

Association of LGR5 and CD44 gene expression levels in residual cancer cells with clinicopathological variables. Elevated LGR5 gene expression was significantly correlated with the absence of vascular invasion $(\mathrm{P}=0.043)$, well differentiated tumor $(\mathrm{P}=0.009)$, and poor pathological response (Rödel system, $\mathrm{P}=0.011$; Ryan system, $\mathrm{P}=0.0037$ ). On the other hand, no significant associations of CD44 gene expression in residual cancer cells with clinicopathological variables were found (Table I).

Correlation of stromal CD44 gene expression with clinicopathological variables. qRT-PCR revealed that 16 of the 52 $(30.8 \%)$ total patients showed detectable CD44 mRNA expression in residual cancer stroma, whereas the remaining patients had no detectable expression despite positive gene expression of $A C T B$. The right side of Table I shows significant correlations of stromal CD44 gene expression with long course radiation $(\mathrm{P}=0.0258)$ and recurrence after curative operation $(\mathrm{P}=0.0004)$ (Table I).

Positive correlation between LGR5 and CD44 gene expression. As shown in Fig. 1, there was a significant positive correlation between expression levels of $L G R 5$ and $C D 44$ in rectal cancer after CRT (Spearman's $\varrho=0.451, \mathrm{P}=0.0014$ ). 
Table I. Tumor characteristics and association of $L G R 5$ and $C D 44$ gene expression levels with clinicopathological variables.

\begin{tabular}{|c|c|c|c|c|c|c|c|c|}
\hline \multirow[b]{2}{*}{ Variables } & \multicolumn{5}{|c|}{ Cancer } & \multicolumn{3}{|c|}{ Stroma } \\
\hline & No. (\%) & $L G R 5$ & $\mathrm{P}$-value & $C D 44$ & P-value & $\begin{array}{c}C D 44 \\
\text { Positive } \\
(\mathrm{n}=16)\end{array}$ & $\begin{array}{c}C D 44 \\
\text { Negative } \\
(\mathrm{n}=36)\end{array}$ & P-value \\
\hline
\end{tabular}

\section{Gender}

\section{Male}

Female

$41(79) \quad 6.394$

$11(21) \quad 2.568$

0.796

0.128

0.536

0.214

$26(50)$

6.477

$26(50)$

6.295

0.640

0.139

0.701

0.130

0.506

0.213

0.165

0.108

35 (67) 6.169

35 (67) $\quad 7.216$

0.845

0.153

0.405

0.107

0.429

0.150

0.654

0.108

19 (36) $\quad 2.934$

13 (25) $\quad 7.253$

0.504

0.185

0.119

0.116

6.132

$21(40) \quad 7.499$

$0.043^{\mathrm{a}}$

0.163

0.150

0.107

$0.009^{\mathrm{a}}$

0.152

0.346

0.099

$0.011^{\mathrm{a}}$

0.174

0.103

0.105

$20(38) \quad 2.032$

$37(71) \quad 10.667$

$0.004^{\mathrm{a}}$

0.150

0.9354

0.108

15 (29) $\quad 2.012$

$42(81) \quad 13.398$

10 (19)

6.151

0.204

0.139

0.852

0.134

$0.043^{\mathrm{a}}$

0.116

0.341

0.197

13

3

28

8

19

17

$\begin{array}{ll}9 & 17\end{array}$

$\begin{array}{rr}5 & 12 \\ 11 & 24\end{array}$

12
24

0.8825

26

0.2571

$\begin{array}{ll}7 & 10\end{array}$

7

24

0.4716

12

11

0.1652

$14 \quad 25$

25

15

0.7775

10

21

5

0.6539

Recurrence

\begin{tabular}{lrrrrrrrr} 
Absent & $37(71)$ & 2.934 & $0.043^{\mathrm{a}}$ & 0.116 & 0.341 & 5 & 31 & $0.0004^{\mathrm{a}}$ \\
Present & $15(29)$ & 12.363 & & 0.197 & & 10 & 6 & \\
\hline
\end{tabular}

$\mathrm{T}$ and $\mathrm{N}$ categories indicate extent of the primary tumor and presence of lymph node metastasis. For gene expression in cancer cells, the value of each target gene is expressed as a median value. Statistical analysis was performed using the Mann-Whitney U test. For gene expression in stromal tissues, the positivity of $C D 44$ is revealed. The significance of the correlation between categorical variables was evaluated using the $\chi^{2}$ test. ${ }^{a} \mathrm{P}<0.05$. 




Figure 2. Immunohistochemistry of LGR5 and CD44. LGR5 was expressed in the cytoplasm of cancer cells (a and b). CD44 was expressed at the membrane of cancer cells and in stromal tissues surrounding residual cancer nests (c and d). Strong immunoreactivity of CD44 in stromal tissue. CD44 expression in stromal cells surrounding cancer nests seems to be stronger than that in cancer cells (e and f). Original magnification x40 (a, c and e), x200 (b, d and f).

Immunohistochemical analysis of LGR5 and CD44. LGR5 expression was detected immunohistochemically at the membrane and in the cytoplasm of cancer cells. CD44 expression was observed at the membrane of cancer cells and in stromal tissue surrounding residual cancer nests (Fig. 2). We divided expression into two groups, high or low, according to immunoreactivity of LGR5 and CD44. There was significant correlation between their immunoreactivities using the $\chi^{2}$ test $(\mathrm{P}=0.0356)$ (data not shown).

Correlation of immunoreactivity of LGR5 and CD44 with clinicopathological variables. The correlation of LGR5 and CD44 immunoreactivities with clinical outcome was evaluated. The LGR5 immunoreactivity of cancer cells was correlated with well differentiated tumor $(\mathrm{P}=0.0196)$. On the other hand, the $\mathrm{CD} 44$ immunoreactivity of cancer cells was correlated with the absence of lymph node metastasis and low postoperative stage $(\mathrm{P}=0.0092$ and 0.00046 , respectively). The strong immunoreactivity of CD44 in stromal cells was correlated with tumor recurrence (Rödel, $\mathrm{P}=0.012$; Ryan, $\mathrm{P}=0.042$, respectively) (Table II).
Correlation of gene expression levels of LGR5 and CD44 with their immunoreactivity. A significant correlation of gene expression of $L G R 5$ with LGR5 immunoreactivity was observed $(\mathrm{P}=0.0062)$. On the other hand, there was a significant correlation between $C D 44$ mRNA levels and its immunoreactivity in cancer stroma $(\mathrm{P}=0.0138)$. Without reaching statistical significance, there was a correlation between $C D 44 \mathrm{mRNA}$ levels and its immunoreactivity in cancer cells $(\mathrm{P}=0.0669)$ (Fig. 3).

Recurrence-free and overall survival after curative surgery. On the basis of these results, receiver operating curve (ROC) analysis was used to identify the cutoff value for $L G R 5$ and for $C D 44$ gene expression levels that were predictive of disease recurrence and patients' death. A nonparametric ROC analysis determined that the optimal cutoff values of $L G R 5$ and $C D 44$ were 6.169 and 0.185 for RFS, and 24.621 and 0.213 for OS. Fig. 4 shows the survival curve for RFS and OS according to $L G R 5$ and $C D 44$ gene expression using Kaplan-Meier method. Patients with $L G R 5$ gene expression levels above 
Table II. Correlation of immunoreactivity of LGR5 and CD44 with clinicopathological variables.

\begin{tabular}{|c|c|c|c|c|c|c|c|c|c|}
\hline \multirow[b]{2}{*}{ Variables } & \multicolumn{3}{|c|}{ LGR5 in cancer } & \multicolumn{3}{|c|}{ CD44 in cancer } & \multicolumn{3}{|c|}{ CD44 in stroma } \\
\hline & $\begin{array}{l}\text { High } \\
(\mathrm{n}=19)\end{array}$ & $\begin{array}{c}\text { Low } \\
(\mathrm{n}=33)\end{array}$ & P-value & $\begin{array}{l}\text { High } \\
(n=11)\end{array}$ & $\begin{array}{c}\text { Low } \\
(n=41)\end{array}$ & P-value & $\begin{array}{l}\text { High } \\
(n=32)\end{array}$ & $\begin{array}{c}\text { Low } \\
(\mathrm{n}=20)\end{array}$ & P-value \\
\hline \multicolumn{10}{|l|}{ Gender } \\
\hline Male & 17 & 24 & 0.155 & 8 & 33 & 0.576 & 24 & 17 & 0.390 \\
\hline Female & 2 & 9 & & 3 & 8 & & 8 & 3 & \\
\hline \multicolumn{10}{|l|}{ Age (median 64.5) } \\
\hline$<65$ & 10 & 16 & 0.773 & 5 & 21 & 0.734 & 15 & 11 & 0.569 \\
\hline$\geq 65$ & 9 & 17 & & 6 & 20 & & 17 & 9 & \\
\hline \multicolumn{10}{|l|}{ урT classification } \\
\hline $1 / 2$ & 4 & 13 & 0.175 & 3 & 14 & 0.666 & 12 & 5 & 0.350 \\
\hline $3 / 4$ & 15 & 20 & & 8 & 27 & & 20 & 15 & \\
\hline \multicolumn{10}{|l|}{ ypN classification } \\
\hline Absent & 15 & 20 & 0.175 & 11 & 24 & $0.009^{\mathrm{a}}$ & 19 & 16 & 0.123 \\
\hline Present & 4 & 13 & & 0 & 17 & & 13 & 4 & \\
\hline \multicolumn{10}{|l|}{ Postoperative stage } \\
\hline $\mathrm{I} / \mathrm{II}$ & 15 & 18 & 0.079 & 11 & 22 & $0.005^{\mathrm{a}}$ & 19 & 14 & 0.439 \\
\hline III & 4 & 15 & & 0 & 19 & & 13 & 6 & \\
\hline \multicolumn{10}{|l|}{ Lymphatic invasion } \\
\hline Absent & 4 & 9 & 0.618 & 5 & 8 & 0.078 & 6 & 7 & 0.188 \\
\hline Present & 15 & 24 & & 6 & 33 & & 26 & 13 & \\
\hline \multicolumn{10}{|l|}{ Vascular invasion } \\
\hline Absent & 8 & 13 & 0.848 & 7 & 14 & 0.077 & 12 & 9 & 0.592 \\
\hline Present & 11 & 20 & & 4 & 27 & & 20 & 11 & \\
\hline \multicolumn{10}{|l|}{ Histology } \\
\hline Well/moderate & 19 & 25 & $0.020^{\mathrm{a}}$ & 10 & 34 & 0.515 & 28 & 16 & 0.466 \\
\hline Poor/signet/mucinous & 0 & 8 & & 1 & 7 & & 4 & 4 & \\
\hline \multicolumn{10}{|l|}{ Rödel TRG } \\
\hline Non-responder, $1 / 2$ & 13 & 19 & 0.439 & 8 & 24 & 0.390 & 24 & 8 & $0.012^{\mathrm{a}}$ \\
\hline Responder, $3 / 4$ & 6 & 14 & & 3 & 17 & & 8 & 12 & \\
\hline \multicolumn{10}{|l|}{ Ryan 3-point TRG } \\
\hline Non-responder, $1 / 2$ & 16 & 21 & 0.115 & 10 & 27 & 0.103 & 26 & 11 & $0.042^{\mathrm{a}}$ \\
\hline Responder, 3 & 3 & 12 & & 1 & 14 & & 6 & 9 & \\
\hline \multicolumn{10}{|l|}{ Radiotherapy } \\
\hline Short & 13 & 29 & 0.087 & 9 & 33 & 0.921 & 26 & 16 & 0.911 \\
\hline Long & 6 & 4 & & 2 & 8 & & 6 & 4 & \\
\hline \multicolumn{10}{|l|}{ Recurrence } \\
\hline Absent & 13 & 24 & 0.741 & 9 & 28 & 0.379 & 20 & 17 & 0.082 \\
\hline Present & 6 & 9 & & 2 & 13 & & 12 & 3 & \\
\hline
\end{tabular}

$\mathrm{T}$ and $\mathrm{N}$ categories indicate extent of the primary tumor and presence of lymph node metastasis. The significance of the correlation between categorical variables was evaluated using the $\chi^{2}$ test. ${ }^{\mathrm{a}} \mathrm{P}<0.05$. 

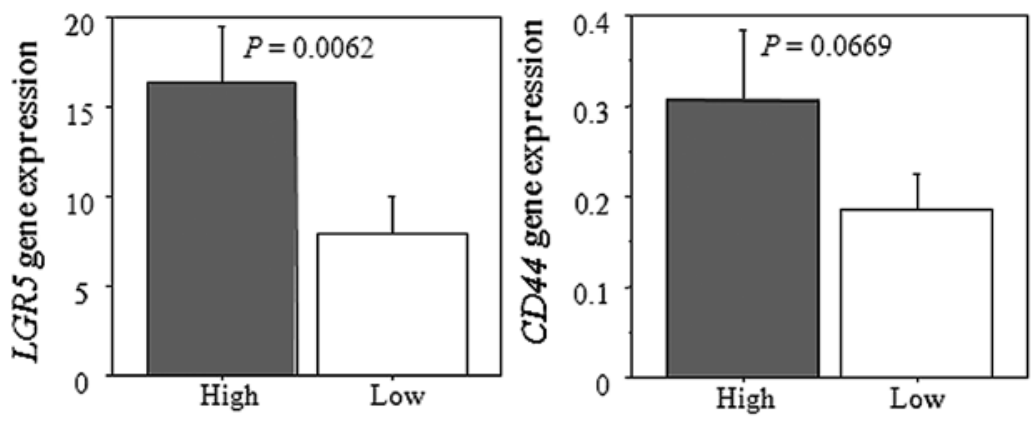

Immunoreactivity of LGR5 in cancer

Immunoreactivity of CD 44 in cancer

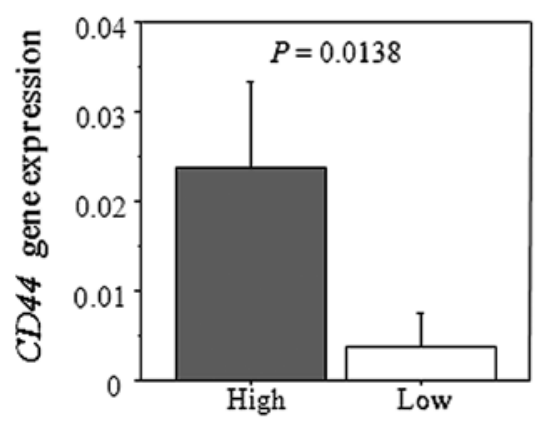

Immunoreactivity of CD44 in stroma

Figure 3. Correlation between LGR5 and CD44 mRNA levels and immunoreactivity of LGR5 and CD44.
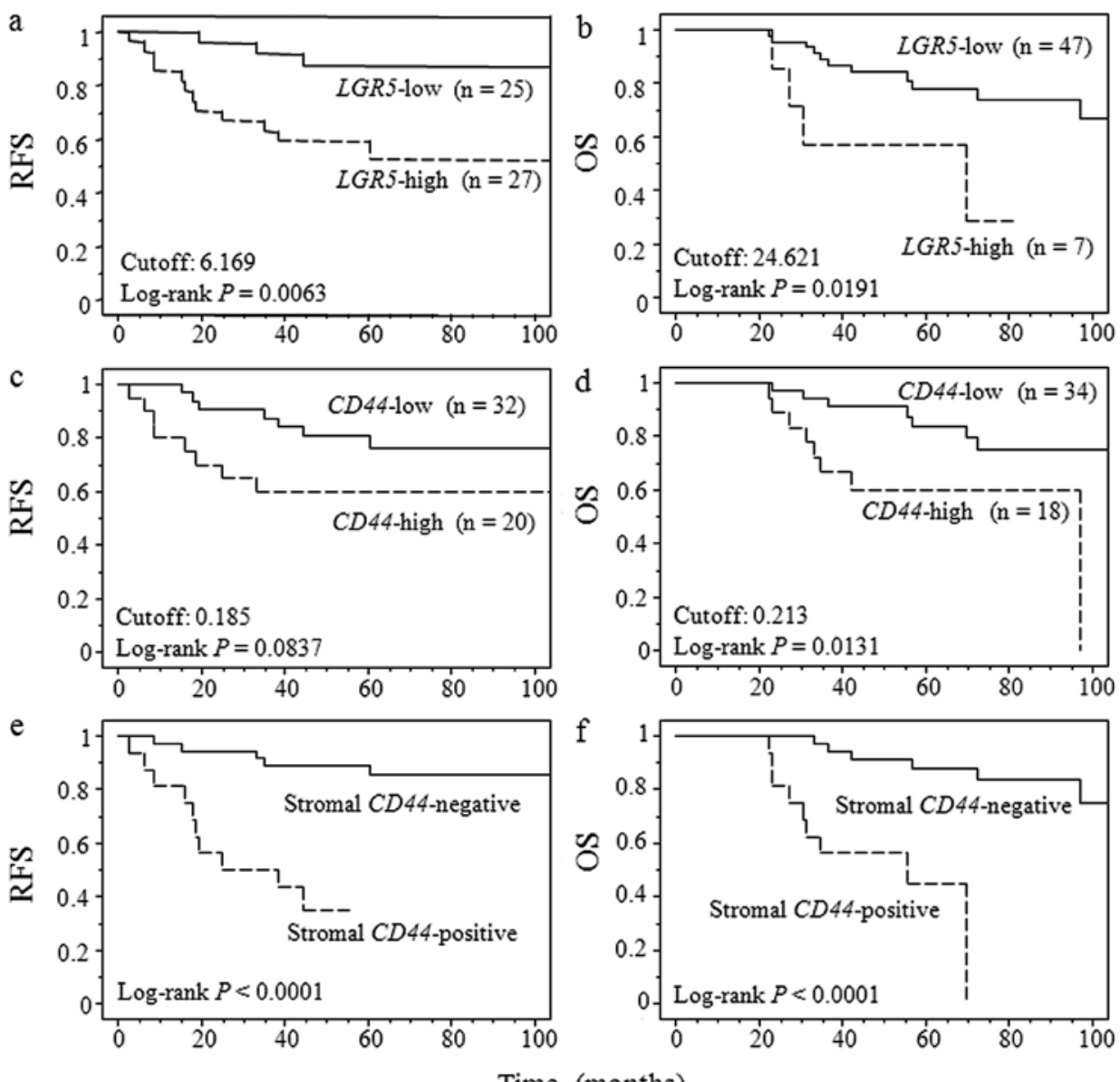

Figure 4. Kaplan-Meier survival curves versus $L G R 5$ and $C D 44$ mRNA levels. Patients with an elevated $L G R 5$ mRNA level had significantly poorer RFS and OS (a and b). Without a statistical significant, there was an association of CD44 mRNA level with RFS (c). Patients with an elevated CD44 mRNA level had significantly poorer OS (d). Patients with positive gene expression of CD44 in stromal tissue had poorer RFS and OS than those with negative expression (e and f). 
Table III. Prognostic value.

A, Univariate and multivariate analyses for tumor recurrence after preoperative CRT

\begin{tabular}{lll}
\hline Variables & HR & 95\% CI \\
\hline Univariate & & P-value \\
Age (<65 vs $\geq 65$ ) & 1.596 & $0.568-4.486$ \\
Rodel TRG (responder vs non-responder) & 3.114 & $0.877-11.064$ \\
Ryan 3-point TRG (responder vs non-responder) & 1.851 & $0.522-6.566$ \\
Pre-stage (I /II vs III) & 2.227 & $0.126-1.591$ \\
Pre-T classification (SI-negative vs -positive) & 1.938 & $0.176-1.512$ \\
Pre-N classification (absent vs present) & 2.227 & 0.3407 \\
Post-stage (I /II vs III) & 2.375 & $0.126-1.591$ \\
ypT classification (T1/2 vs T3/4) & 0.917 & $0.153-1.163$ \\
ypN classification (absent vs present) & 2.188 & $0.372-3.193$ \\
LGR5 (<cutoff vs $\geq$ cutoff ) & 4.942 & $0.165-1.261$ \\
$C D 44$ (< cutoff vs $\geq$ cutoff ) & 2.389 & $1.390-17.577$ \\
Stroma $C D 44$ (negative vs positive) & 8.065 & 0.2145 \\
Stroma CD44 (low vs high) & 3.163 & 0.0951 \\
Multivariate & & 0.8743 \\
LGR5 (< cutoff vs $\geq$ cutoff ) & & 0.1305 \\
Stroma $C D 44$ (negative vs positive) & 3.350 & $0.0139-0.398$ \\
\hline
\end{tabular}

B, Univariate and multivariate analyses for survival after preoperative CRT

\begin{tabular}{|c|c|c|c|}
\hline Variables & HR & $95 \% \mathrm{CI}$ & P-value \\
\hline \multicolumn{4}{|l|}{ Univariate } \\
\hline Age $(<65$ vs $\geq 65)$ & 1.855 & $0.673-5.111$ & 0.2319 \\
\hline Rodel TRG (responder vs non-responder) & 1.594 & $0.551-4.613$ & 0.3899 \\
\hline Ryan 3-point TRG & 1.915 & $0.545-6.731$ & 0.3112 \\
\hline Pre-stage (I /II vs III) & 0.724 & $0.233-2.251$ & 0.5768 \\
\hline Pre-T classification (SI-negative vs -positive) & 0.638 & $0.211-1.844$ & 0.4070 \\
\hline Pre-N classification (absent vs present) & 0.311 & $0.233-2.251$ & 0.5768 \\
\hline Post-stage (I /II vs III) & 0.382 & $0.141-1.037$ & 0.0588 \\
\hline ypT classification (T1/2 vs T3/4) & 0.875 & $0.276-2.772$ & 0.8208 \\
\hline ypN classification (absent vs present) & 0.575 & $0.212-1.561$ & 0.2778 \\
\hline Recurrence (absent vs present) & 4.292 & $0.085-0.635$ & $0.0044^{\mathrm{a}}$ \\
\hline$L G R 5$ (< cutoff vs $\geq$ cutoff $)$ & 3.684 & $1.146-11.846$ & $0.0287^{\mathrm{a}}$ \\
\hline$C D 44$ (< cutoff vs $\geq$ cutoff $)$ & 3.476 & $1.225-9.861$ & $0.0192^{\mathrm{a}}$ \\
\hline Stroma $C D 44$ (negative vs positive) & 9.743 & $0.032-0.370$ & $0.0004^{\mathrm{a}}$ \\
\hline Stroma $C D 44$ (low vs high) & 2.213 & $0.710-6.895$ & 0.1708 \\
\hline \multicolumn{4}{|l|}{ Multivariate } \\
\hline Recurrence (absent vs present) & 2.160 & $0.144-1.487$ & 0.1958 \\
\hline$L G R 5$ (< cutoff vs $\geq$ cutoff $)$ & 1.061 & $0.299-3.771$ & 0.9267 \\
\hline$C D 44(<$ cutoff vs $\geq$ cutoff $)$ & 2.105 & $0.667-6.645$ & 0.2044 \\
\hline Stroma $C D 44$ (negative vs positive) & 4.630 & $0.047-0.994$ & $0.0491^{\mathrm{a}}$ \\
\hline
\end{tabular}

SI, serosal invasion; TRG, tumor regression grade; HR, hazard ratio; CI, confidence interval. ${ }^{\mathrm{a}} \mathrm{P}<0.05$.

cutoff values showed a significantly poorer RFS and OS than did patients with expression levels below cutoff values (RFS; $\mathrm{P}=0.0063$, OS; $\mathrm{P}=0.0191$ ). While, $C D 44$ gene expression levels above cutoff values showed a significantly poorer OS than did patients with expression levels below cutoff values although CD44 gene expression level did not have a significant associa- 
tion with RFS (RFS; $\mathrm{P}=0.0837$, OS; $\mathrm{P}=0.0131$ ). On the other hand, patients with positive $C D 44$ gene expression in cancer stroma showed significantly worse RFS and OS $(\mathrm{P}<0.0001)$. RFS and OS according to the immunoreactivity of LGR5 and CD44 did not show the significant difference (data not shown).

Predictive value of LGR5 and CD44 gene expression levels for tumor recurrence and survival. Table III shows the results of univariate and multivariate analyses of factors influencing patients' prognosis using Cox's proportional hazards model. univariate analysis showed that cancer $L G R 5$ expression and positivity of stromal $C D 44$ gene expression levels were significantly associated with a higher rate of developing recurrence after preoperative CRT ( $\mathrm{P}=0.0136$ and 0.0005 , respectively). In a multivariate analysis, a positivity of stromal $C D 44$ gene expression was found to be an independent predictive marker for disease recurrence after preoperative CRT $(\mathrm{P}=0.0028)$ (Table IIIA). On the other hand, univariate analysis showed that the following factors were significantly related to postoperative overall survival: disease recurrence, cancer $L G R 5$, $C D 44$ gene expression level and positivity of stromal $C D 44$ gene expression $(\mathrm{P}=0.0044,0.0287,0.0192$ and 0.0004 , respectively). Multivariate analysis indicated that positivity of stromal $C D 44$ gene expression was an independent prognostic factor for the overall survival of patients with rectal cancer after preoperative CRT ( $\mathrm{P}=0.0491)$ (Table IIIB). The clinical variables before CRT seemed not to be influenced in patient prognosis after CRT.

\section{Discussion}

Preoperative CRT for locally advanced rectal cancer is an effective tool for local control because it induces cancer cell apoptosis and death, and inhibits cell growth in various malignancies $(2,31)$. However, the mechanism of tumor relapse in rectal cancer after preoperative CRT has been not fully elucidated. Actually, clinicopathological variables including TNM classification in pre-CRT was not influenced in patient prognosis after CRT in the present study. To clarify the characteristics of cancer cells after CRT, it is necessary to reevaluate the expression of genes and proteins associated with clinical outcome because the characteristics of cancer cells after CRT may be different from those of primary cancer cells prior to treatment. The identification of predictive markers for recurrence or poor prognosis should improve both clinical outcome and potential treatment stratification for such patients. Therefore, we focused the expression of genes and proteins after preoperative CRT.

CSCs are a small sub-population of cancer cells that possess stem cell-like properties such as self-renewal and the ability to differentiate into multiple cell types. Recent research suggests that CSCs are particularly resistant to conventional CRT compared with non-CSCs (13-15,32). These lines of evidence prompted us to hypothesize that CSCs survive CRT and are associated with resistance to CRT and tumor relapse after CRT. CD44 is a candidate marker for colon CSCs (13-15), while LGR5 is a potential marker for stem cells in the small intestine and colon (5-7). We found a significant positive correlation between LGR5 and CD44 protein expression and between LGR5 and CD44 gene expression in cancer cells after CRT using transcriptional and immunohistochemical analyses. Both these markers have been known as targets of Wnt signaling. Wnt signaling has emerged as a critical regulator of stem cells and the its pathway is integrally involved in both stem cell and cancer cell maintenance and growth (33). Kanwar et al reported that $\mathrm{Wnt} / \beta$-catenin signaling plays a critical role in the growth and maintenance of colonospheres and the inhibition of $\beta$-catenin results in a marked reduction in CD44-positive cells as well as colonospheres formation (34). While, it has been reported that LGR5 expression is associated with activation of the Wnt pathway (35). We immunohistochemically examined the expression of $\beta$-catenin as Wnt target molecule and observed its expression in residual cancer cells with both LGR5 and CD44 expression (data not shown). Although our study did not demonstrate the direct correlation between LGR5 and CD44, these expressions might have any interaction via Wnt signaling pathway.

We observed that elevated $L G R 5$ expression in cancer cells and CD44 expression in cancer stroma, but not cancer cells were significantly correlated with poor pathological response. Additionally, elevated gene expression of $L G R 5$ in cancer cells and positive gene expression of $C D 44$ in cancer stroma were significantly associated with poor RFS, and elevated gene expression of $L G R 5$ and $C D 44$ in cancer cells and positive gene expression of $C D 44$ in cancer stroma were significantly associated with poor OS. These results suggested that both LGR5 and $C D 44$ gene expression were useful prognostic markers of patients with rectal cancer after preoperative CRT. Especially, CD44 gene expression in both cancer cells and stroma was an independent prognostic factor for the RFS and OS. Without reaching statistical significance, there was the association of poor recurrence-free survival with CD44 immunoreactivity in cancer stroma (log-rank test; $\mathrm{P}=0.060$ ). $\mathrm{CD} 44$ is an important mediator in regulating interaction between ECM and the intracellular actin cytoskeleton. CD44 are considered to generate a number of cellular signals which play critical roles in not only cancer invasion and metastasis, but also various physiological and pathological processes $(12,16,18)$. In the present study, our results emphasized the significance of CD44 expression in not only cancer cells but also cancer stromal tissue. However, there were some discrepancy of the results between gene expression level and immunoreactivity of these markers although the correlation between these gene and protein expressions was observed. Immunohistochemistry, western blotting, and other protein-quantification methods do not always corroborate RT-qPCR data. For CD44, we used the monoclonal antibody for CD44 immunostaining included variant 3-10. Previous reports demonstrated that overexpression of the standard CD44 isoform resulted in decreased tumorigenesis and tumor progression in vitro (36). Some studies indicated that high expression of CD44v6 was associated with primary tumors and was a predictor of metastasis, including colon cancer $(11,37)$. Taken together, whether CD44 promotes or protects against tumor progression may depend on the isoform. Hence, to clarify the function of CD44, we plan to further investigate the differences of expression according to each splice variant.

In conclusion, there was a significant positive correlation between LGR5 and CD44 expression and elevated these expressions were associated with poor prognosis. Our results suggest that LGR5 and CD44 may contribute to tumor relapse in locally advanced rectal cancer treated with preoperative CRT. 
However, data in this study should be interpreted with some caution. First of all, the major limitations were the small number of patients $(n=52)$, especially those with a recurrence $(n=15)$, and the retrospective nature of the study. Second, this study included two neoadjuvant radiation regimens with different time interval between pretreatment and surgery. Third, our short-course regimen was different from standard one. A larger study population, a long-term follow-up and the unification of pretreatments are needed to validate these results.

\section{Acknowledgements}

The authors would like to thank Motoko Ueeda, Yuka Kato, and Chihiro Hibi for providing excellent technical assistance.

\section{References}

1. Sauer R, Becker H, Hohenberger W, et al: Preoperative versus postoperative chemoradiotherapy for rectal cancer. N Engl J Med 351: 1731-1740, 2004.

2. Sebag-Montefiore D, Stephens RJ, Steele R, et al: Preoperative radiotherapy versus selective postoperative chemoradiotherapy in patients with rectal cancer (MRC CR07 and NCIC-CTG C016): a multicentre, randomised trial. Lancet 373: 811-820, 2009.

3. Bosset JF, Collette L, Calais G, et al: Chemotherapy with preoperative radiotherapy in rectal cancer. N Engl J Med 355: $1114-1123,2006$.

4. Guillem JG, Chessin DB, Cohen AM, et al: Long-term oncologic outcome following preoperative combined modality therapy and total mesorectal excision of locally advanced rectal cancer. Ann Surg 241: 829-838, 2005.

5. Barker N, van Es JH, Kuipers J, et al: Identification of stem cells in small intestine and colon by marker gene Lgr5. Nature 449: 1003-1007, 2007.

6. Becker L, Huang Q and Mashimo H: Immunostaining of Lgr5, an intestinal stem cell marker, in normal and premalignant human gastrointestinal tissue. Sci World J 8: 1168-1176, 2008.

7. Haegebarth A and Clevers H: Wnt signaling, lgr5, and stem cells in the intestine and skin. Am J Pathol 174: 715-721, 2009.

8. Sato T, Vries RG, Snippert HJ, et al: Single Lgr5 stem cells build crypt-villus structures in vitro without a mesenchymal niche. Nature 459: 262-265, 2009.

9. Barker N, Ridgway RA, van Es JH, et al: Crypt stem cells as the cells-of-origin of intestinal cancer. Nature 457: 608-611, 2009.

10. Uchida H, Yamazaki K, Fukuma M, et al: Overexpression of leucine-rich repeat-containing $\mathrm{G}$ protein-coupled receptor 5 in colorectal cancer. Cancer Sci 101: 1731-1737, 2010.

11. Ponta H, Sherman L and Herrlich PA: CD44: from adhesion molecules to signalling regulators. Nat Rev Mol Cell Biol 4: 33-45, 2003.

12. Nagano $\mathrm{O}$ and Saya $\mathrm{H}$ : Mechanism and biological significance of CD44 cleavage. Cancer Sci 95: 930-935, 2004

13. Reya T, Morrison SJ, Clarke MF, et al: Stem cells, cancer, and cancer stem cells. Nature 414: 105-111, 2001.

14. Vermeulen L, Sprick MR, Kemper K, et al: Cancer stem cells - old concepts, new insights. Cell Death Differ 15: 947-958, 2008.

15. Thenappan A, Li Y, Shetty K, et al: New therapeutics targeting colon cancer stem cells. Curr Colorectal Cancer Rep 5: 209, 2009.
16. Marhaba R and Zoller M: CD44 in cancer progression: adhesion, migration and growth regulation. J Mol Histol 35: 211-231, 2004.

17. Subramaniam V, Vincent IR, Gardner H, et al: CD44 regulates cell migration in human colon cancer cells via Lyn kinase and AKT phosphorylation. Exp Mol Pathol 83: 207-215, 2007.

18. Jothy S: CD44 and its partners in metastasis. Clin Exp Metastasis 20: 195-201, 2003.

19. Lopez JI, Camenisch TD, Stevens MV, et al: CD44 attenuates metastatic invasion during breast cancer progression. Cancer Res 65: 6755-6763, 2005.

20. Lakshman M, Subramaniam V, Rubenthiran U, et al: CD44 promotes resistance to apoptosis in human colon cancer cells. Exp Mol Pathol 77: 18-25, 2004.

21. Zeki SS, Graham TA and Wright NA: Stem cells and their implications for colorectal cancer. Nat Rev Gastroenterol Hepatol 8: 90-100, 2011.

22. Wielenga VJ, Smits R, Korinek V, et al: Expression of CD44 in Apc and Tcf mutant mice implies regulation by the WNT pathway. Am J Pathol 154: 515-523, 1999.

23. Kim BM, Mao J, Taketo MM, et al: Phases of canonical Wnt signaling during the development of mouse intestinal epithelium. Gastroenterology 133: 529-538, 2007.

24. Yoshikawa R, Kusunoki M, Yanagi H, et al: Dual antitumor effects of 5-fluorouracil on the cell cycle in colorectal carcinoma cells: a novel target mechanism concept for pharmacokinetic modulating chemotherapy. Cancer Res 61: 1029-1037, 2001.

25. Fowler JF: The linear-quadratic formula and progress in fractionated radiotherapy. Br J Radiol 62: 679-694, 1989.

26. Viani GA, Stefano EJ, Soares FV, et al: Evaluation of biologic effective dose and schedule of fractionation for preoperative radiotherapy for rectal cancer: meta-analyses and meta-regression. Int J Radiat Oncol Biol Phys 80: 985-991, 2011.

27. Rodel C, Martus P, Papadoupolos T, et al: Prognostic significance of tumor regression after preoperative chemoradiotherapy for rectal cancer. J Clin Oncol 23: 8688-8696, 2005.

28. Ryan R, Gibbons D, Hyland JM, et al: Pathological response following long-course neoadjuvant chemoradiotherapy for locally advanced rectal cancer. Histopathology 47: 141-146, 2005.

29. Saigusa S, Tanaka K, Toiyama Y, et al: Correlation of CD133, OCT4, and SOX2 in rectal cancer and their association with distant recurrence after chemoradiotherapy. Ann Surg Oncol 16: 3488-3498, 2009.

30. Bijwaard KE, Aguilera NS, Monczak Y, et al: Quantitative real-time reverse transcription-PCR assay for cyclin D1 expression: utility in the diagnosis of mantle cell lymphoma. Clin Chem 47: 195-201, 2001.

31. Watanabe T: Chemoradiotherapy and adjuvant chemotherapy for rectal cancer. Int J Clin Oncol 13: 488-497, 2008.

32. Bao S, Wu Q, McLendon RE, et al: Glioma stem cells promote radioresistance by preferential activation of the DNA damage response. Nature 444: 756-760, 2006.

33. Reya $\mathrm{T}$ and Clevers $\mathrm{H}$ : Wnt signalling in stem cells and cancer. Nature 434: 843-850, 2005.

34. Kanwar SS, Yu Y, Nautiyal J, et al: The Wnt/beta-catenin pathway regulates growth and maintenance of colonospheres. Mol Cancer 9: 212, 2010.

35. Takahashi H, Ishii H, Nishida N, et al: Significance of Lgr5(+ve) cancer stem cells in the colon and rectum. Ann Surg Oncol 18: 1166-1174, 2011.

36. Choi SH, Takahashi K, Eto H, et al: CD44s expression in human colon carcinomas influences growth of liver metastases. Int $\mathrm{J}$ Cancer 85: 523-526, 2000.

37. Mulder JW, Wielenga VJ, Polak MM, et al: Expression of mutant p53 protein and CD44 variant proteins in colorectal tumorigenesis. Gut 36: 76-80, 1995. 